Disponível em

http://www.anpad.org.br/rac

RAC, Rio de Janeiro, v. 17, n. 5, art. 1, pp. 518-535, Set./Out. 2013

$($ co) EY-No

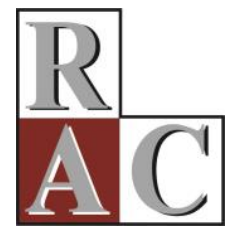

\title{
Desconstrução do Mito e Sucessão do Fundador em Empresas Familiares
}

\section{Deconstruction of Founder Myths and Succession in Family Businesses}

Antonio Carlos Soares Pereira E-mail: adm.antonioc@ig.com.br

Faculdade Novos Horizontes Rua Alvarenga Peixoto, 1270, 30180-121, Belo Horizonte, MG, Brasil.

Adriane Vieira

E-mail: vadri.bh@gmail.com Universidade Federal de Minas Gerais - UFMG Av. Alfredo Balena, 190, 30130-100, Belo Horizonte, MG, Brasil.

Fernando Coutinho Garcia

E-mail: garciafc.bh@gmail.com

Faculdade Novos Horizontes Rua Alvarenga Peixoto, 1270, 30180-121, Belo Horizonte, MG, Brasil.

Maria Teresa de Azeredo Roscoe

E-mail: teroscoe@fdc.org.br

Fundação Dom Cabral - FDC Av. Princesa Diana, 760, Alphaville, 34000-000, Nova Lima, MG, Brasil. 


\title{
Resumo
}

Mitos funcionais promovem a estruturação da empresa e dos relacionamentos interpessoais; no entanto, tornamse disfuncionais quando dificultam o processo sucessório. O objetivo geral da pesquisa consistiu em identificar os fatores que contribuem para a desconstrução de um mito em uma empresa familiar que passa pelo processo de sucessão do fundador, e em analisar como o estágio do mito se relaciona com o desenvolvimento sistêmico da organização. O método de pesquisa utilizado foi o estudo de caso. A análise dos dados revela que os fatores que mais contribuíram para a desconstrução do mito foram: a sua recusa em abordar temas relacionados a conflitos familiares; o comportamento de centralização e autoritarismo do mito; e a não transmissão do empreendedorismo para a geração sucessora. Na dimensão propriedade, o Grupo encontra-se no estágio inicial, de proprietário controlador, mas o desejo de substituir o fundador-mito tem levado à transição para o estágio de sociedade entre irmãos; na dimensão família, o Grupo está na fase de passagem do bastão, mesmo com a resistência do fundador-mito; e, por fim, na dimensão empresa, encontra-se em expansão/formalização, apesar da existência de conflitos latentes entre os membros da família.

Palavras-chave: empresa familiar; sucessão; fundador; mito.

\begin{abstract}
Functional myths promote business and interpersonal relationship structure, however, they become dysfunctional when they hinder the succession process. This research's objective was to identify the factors that contribute to the deconstruction of a myth in a family business that goes through the process of succession from the founder, and analyze how the myth relates to the development of systemic organization. The research method used was the case study. Data analysis revealed that the factors that contributed to the deconstruction of the myth were: a refusal to address issues related to family conflicts; centralization and authoritarian behavior about the myth; and not transmitting a sense of entrepreneurship to the successive generation. In the property dimension, the Group is in the initial stage and controlled by the owner, but the desire to replace the founding-myth has led to a transition to a state of society among siblings; in the family dimension, the Group is in the process of passing the baton, despite resistance from the founding-myth; and, finally, the corporate dimension is a state of expansion/formalization, despite the existence of underlying conflicts between family members.
\end{abstract}

Key words: family business; succession; founder; myth. 


\section{Introdução}

Segundo Casillas, Vázquez e Díaz (2007), as diferentes definições de empresa familiar giram em torno de três aspectos fundamentais: o controle sobre a empresa; o poder que a família exerce sobre a empresa; e a inclusão dos membros da família na gestão, com a intenção de transferir a propriedade a outras gerações. Essas multidimensões são representadas pela tríade família, gestão e propriedade, que age como sistemas que interagem entre si. Essa perspectiva sistêmica permite analisar a dinâmica das empresas familiares em seu contexto, identificar os múltiplos fatores relacionais internos e externos, e compreender como os padrões de comportamento e de inter-relações se originam e se estabilizam, constituindo a cultura das empresas e suas referências de lideranças.

Em situações de ameaça, um dos grandes desafios da família é manter vivos os propósitos do fundador e a cultura empresarial por ele criada. Para que isso aconteça, a memória da empresa é criada por meio de rituais, arquivamentos e exposições de documentos de modo a manter vivo o mito fundador, transformando-o em uma figura de referência e modelo a ser seguido (L. Nicholson \& Anderson, 2005).

Embora a literatura sobre empresas familiares aborde com frequência a complexidade do processo de sucessão (Chittoor \& Das, 2007; Flores \& Grisci, 2012; Massis, Chua, \& Chrisman, 2008; Pontet, Wrosch, \& Gagne, 2007; Waiandt \& Davel, 2008) e os conflitos familiares decorrentes, a constituição do fundador como mito, sua influência na condução dos negócios e nas relações familiares e, em particular, no seu próprio processo de sucessão, têm recebido pouca atenção dos pesquisadores.

Para Ziemer (1996), os mitos organizacionais possuem funções de organização e estruturação, tais como: definir rotinas e regras, analisar eventos passados e apontar soluções no presente e no futuro, diminuir incertezas e complexidades, ajudar na definição de uma identidade organizacional e fazer cumprir os compromissos com ideais e valores da empresa. Esse é o papel funcional dos fundadores tornados mitos, no entanto, quando eles próprios passam a dificultar o processo sucessório e o desenvolvimento da empresa e dos membros da família, impedindo que gestores e herdeiros inovem e estabeleçam modos de gerir diferentes dos seus, o mito pode se tornar disfuncional e comprometer a permanência do negócio na família. Ainda de acordo com o autor citado, mitos normalmente surgem da interação das tendências inatas de cada pessoa, das suas experiências de vida, e são criados inconscientemente e aceitos pelos que os rodeiam de forma espontânea, mas sua condição não é imutável, ou seja, eles podem passar por diferentes estágios de evolução, que vão do desenvolvimento à maturação do mito, mas também de declínio à reformulação.

O tema deste artigo é o processo de sucessão de um fundador considerado mito. Como propõe Cadieux (2007), abordamos a sucessão a partir da interação entre o antecessor e os sucessores durante o processo de desenvolvimento da empresa.

O objetivo geral da pesquisa consistiu em identificar os fatores que contribuem para a desconstrução de um mito em uma empresa familiar que passa pelo processo de sucessão do fundador e em analisar como o estágio do mito-fundador se relaciona com o desenvolvimento sistêmico da organização nas dimensões: família, propriedade e empresa.

O pressuposto da pesquisa é o de que o fundador-mito tem como papel central criar a cultura organizacional, e de que, mesmo culturas centradas no fundador, podem promover renovação quando a geração sucessora interage com o fundador nas decisões estratégicas, o que é condição necessária para a construção de relações em que a autonomia e a proatividade são preservadas e estimuladas. Em situação contrária, o mito se torna disfuncional e ameaça a sobrevivência da empresa, por impedir a transmissão do empreendedorismo através das gerações.

O método de investigação utilizado foi o estudo de caso do tipo interpretativo, e a escolha dos sujeitos da pesquisa se deu pelo critério de intencionalidade e acessibilidade. Os dados foram 
coletados por meio de oito entrevistas semiestruturadas e de observações livres, e foram analisados por meio da técnica de análise de conteúdo. A unidade de observação foi um grupo empresarial familiar, localizado em Minas Gerais, com mais de 20 anos de existência. Na sequência deste artigo, apresentase o referencial teórico, a metodologia de pesquisa, a descrição e a análise de dados, e as considerações finais.

\section{O Fundador e o Mito Familiar}

Existem várias abordagens presentes na literatura especializada que oferecem perspectivas múltiplas e complementares a respeito do tema mito. $\mathrm{O}$ mito pode ser considerado um relato sobre seres e acontecimentos imaginários de épocas heroicas, ideia falsa ou distorcida da realidade, ou ainda pessoa, fato ou coisa real valorizado pela imaginação popular, cuja história é construída e mantida por discursos, documentos, imagens e fotografias, com o objetivo de construir valores e fornecer uma lente interpretativa e prescritiva, que ensina como lidar com a realidade (Henrique \& Gomes, 2005; Panichi, 2007; Prado, 2000).

No sentido grego, a palavra mythos refere-se à narração pública dos feitos lendários de uma comunidade (Oliveira, Pereira, Silva, \& Brito, 2008). Na acepção antropológica, de acordo com Chauí (2000), essa narrativa assume uma solução imaginária para tensões, conflitos e contradições, como resposta a situações injustificadas do mundo real.

O mito fundador, segundo Chauí (2000), impõe um vínculo interno com o passado de origem, que se conserva no presente, e que, por isso mesmo, não permite que se compreenda o presente enquanto tal. As marcas da fundação são a transcendência e a imanência do momento fundador. "Um mito fundador é aquele que não cessa de encontrar novos meios para exprimir-se, novas linguagens, novos valores e ideias, de tal modo que, quanto mais parece ser outra coisa, tanto mais é a repetição de si mesmo" (Chauí, 2000, p. 5).

Nesse sentido, fala-se no mito também na acepção psicanalítica, ou seja, como um impulso à repetição de algo imaginário, impedindo a percepção da realidade (Azevedo, 2004; Henrique \& Gomes, 2005; Panichi, 2007). Os mitos, portanto, são compreendidos como modelos de subjetivação que moldam nossas mentes. "Eles nos criam, nós os servimos e eles nos vivem" (Pontanari, 2008, p. 67), enquanto uma produção coletiva e também cultural. O mito está contido em material verbal ou paraverbal, como expressão coletiva "possuidora de vida, de partes de subjetividades, compreendida em sentido como histórias verdadeiras, abarcando lendas urbanas, as histórias de grupos vários e pessoais, além das muitas expressões das artes" (Pontanari, 2008, p. 68).

As narrativas das empresas familiares são construídas em torno da figura do fundador, ele é a própria empresa, e a história da família mescla-se com a história dele e a da construção do negócio, que será transmitido às futuras gerações de herdeiros. Ele é o elemento catalisador em torno do qual a história da própria família e da empresa é contada e recontada. Ele une e congrega todos, dá a direção, constrói o conjunto de crenças em torno do qual os membros da família permanecem unidos. Nesse sentido, ele é o próprio mito. É ele que mantém a concordância grupal e fortalece os papéis de cada um. Em troca, os membros devem manter uma relação de lealdade com o mito e entre si (Armstrong, 2005; Falcke \& Wagner, 2005; Panichi, 2007; Pontanari, 2008).

Importante contribuição é dada por Prado (2000), ao esclarecer que o mito familiar é composto não apenas pelos discursos e narrativas, mas também pelos não ditos ou até pelos não pensados, associados aos fatos e situações que geram sofrimento e toxidade relacional. No entanto, o mito familiar também é transmitido, não por meio de palavras, mas pelo desejo do outro (Rosa, 2001), que, em momentos de mudanças, acompanhadas ou não por crises, como as de sucessão familiar, pode eclodir em forma de conflitos, angústias, agressões, que devem ser terapeuticamente abordados (Kets De Vries, Carlock, \& Florent-Treacy, 2009). 


\section{Modelo Tridimensional de Desenvolvimento}

Uma referência para a análise sistêmica de uma empresa familiar é o modelo de Três Círculos de Gersick, Davis, Hampton e Lansberg (2006), que representa a inter-relação entre os subsistemas família, propriedade e empresa. Tal modelo de análise foi construído tendo como referência estudos desenvolvidos por Tagiuri e Davis (1996), que focavam apenas dois dos subsistemas superpostos: família e gestão. Na visão de Gersick et al. (2006), fazia-se necessário distinguir o gerenciamento da propriedade, por isso os autores incluíram mais uma dimensão. Além disso, os membros da família desempenham simultaneamente três papéis: gestores, proprietários e parentes (Carter \& Schwab, 2008). Isso torna as organizações familiares híbridas, pois elas incorporam as relações de negócios na própria família e vive-versa. O modelo desenvolvido por Gersick et al. (2006) permite analisar o desenvolvimento da empresa como um todo. Desse modo, empregados que não fazem parte da família podem alterar sua localização na medida em que passam a receber participação acionária. O mesmo acontece com um executivo que é, ao mesmo tempo, membro da família e se aposenta, gerando alterações na dinâmica dos Três Círculos. Para os autores, essas progressões de desenvolvimento influenciam-se umas às outras, mas também são independentes. Cada parte muda em seu ritmo próprio e de acordo com sua sequência, por isso, deve-se considerar a evolução das variáveis família, propriedade e gestão de forma independente e atemporal (Gersick, Davis, Hampton, \& Lansberg, 2006). A partir dessas considerações, os autores elaboraram o Modelo Tridimensional de Desenvolvimento, que contém três eixos compostos por fases.

Segundo Gersick et al. (2006), o eixo propriedade contém as fases: proprietário controlador, associação de irmãos e consórcio de primos. O eixo empresa é formado pelas fases: momento da fundação, processo de expansão e de formalização e maturidade. Por fim, o eixo da família apresenta quatro fases: família empresária jovem, entrada para a empresa, trabalho em conjunto e transferência de poder.

Essa última fase do eixo família diz respeito à sucessão, definida por Scheffer (1995, p. 81) como "o rito de transferência de poder e de capital entre a geração que atualmente dirige e a que virá a dirigir" os negócios da família, podendo acontecer de forma gradativa e planejada ou de forma repentina, em função de morte ou adoecimento do dirigente. Infelizmente, de acordo com Brenes, Madrigal e Molina-Navarro (2006) e Massis, Chua e Chrisman (2008), são poucos os fundadores que dedicam atenção ao planejamento de sua aposentadoria e sucessão, ocasionando problemas que, na maioria das vezes, poderiam ser antecipadamente resolvidos. A escolha da pessoa que assumirá os negócios normalmente é realizada sob questões subjetivas, enquanto os fatores ligados à competência técnica e à capacidade de liderança, segundo Gueiros e Oliveira (2000) e Kellermanns, Eddleston, Barnett, e Pearson (2008), na maioria das vezes, ficam em segundo plano.

Os estágios da sucessão compreendem o ingresso dos herdeiros nos negócios da família, sua familiarização com a cultura, o processo de trabalho, a gradativa assimilação dos conhecimentos necessários para gerenciá-los até a efetiva sucessão (Longenecker, Moore, \& Petty, 1997). Esse aprendizado não se resume ao local de trabalho, ao contrário, envolve o tempo em que pais e filhos passam juntos conversando, interagindo, compartilhando práticas e fortalecendo os laços familiares e empresariais (Davis \& Tagiuri, 1989; Kets De Vries et al., 2009), pois, para que as empresas familiares atinjam o crescimento contínuo, elas devem passar o espírito empresarial e as capacidades que lhes permitam criar novos fluxos de riqueza entre muitas gerações (Brundin, Nordvist, \& Melin, 2011; Habbershon, Nordavist, \& Zelleweger, 2011; Vieira, Sousa, \& Roscoe, 2012).

Como alertam De Freyman, Richomme-Huet e Paturel (2006) e De Freyman e Richomme-Huet, (2010), o processo de sucessão envolve não só a transferência de capital físico e humano, como também de capital social, ou seja, os laços sociais, as relações de confiança e os sistemas de valores que facilitam ações de indivíduos localizados dentro do contexto. O capital social é o complemento do capital humano que, por sua vez, está associado a uma qualidade criada entre pessoas. Na visão de Bayad e Barbot (2002), existem algumas condições que precisam ser atingidas pelo sucessor para que 
este obtenha sucesso na transmissão gerencial, tais como: aceitabilidade, credibilidade, legitimidade e liderança. As experiências infantis e familiares precoces, instrução e formação, e certas experiências de trabalho encorajam um comportamento empreendedor e facilitam a aceitabilidade do sucessor na empresa. As competências adquiridas por meio dessas experiências estão relacionadas ao capital social. A credibilidade pode ser conseguida quando o sucessor é encorajado a participar do planejamento para o crescimento e a estabilidade da empresa. As competências adquiridas por meio dessas experiências, por sua vez, estão mais relacionadas com o capital humano. A aceitabilidade e a credibilidade são requisitos que reforçam a legitimidade do sucessor e permitem que ele passe a confiar em si mesmo e nos funcionários da empresa, assumindo posição de liderança. De acordo com Borges, Carvalho e Lima (2007), para suceder o fundador, é preciso que o herdeiro tenha competências e condições de dar continuidade aos negócios, estabelecendo novas visões de futuro sem colocar em risco o patrimônio da família.

Em função das peculiaridades das empresas familiares, Kets De Vries, Carlock e Florent-Treacy (2009) argumentam ser necessário acrescentar, ao modelo sistêmico familiar de análise, conceitos e teorias extraídos da psicologia psicodinâmica, que são provenientes da psicanálise, para o entendimento das forças psicológicas, às vezes, inconscientes, que agem sobre o comportamento humano, como forma de se desenvolver uma visão mais completa e equilibrada dos comportamentos individuais e das relações familiares. De acordo com os autores, estudos revelam que os conflitos existentes entre familiares, com frequência, afetam a dimensão empresa, espaço no qual pais e filhos disputam o controle e o afeto. Em empresas familiares na América do Sul, Ásia, África e Oriente Médio, o modelo patriarcalista e paternalista ainda é predominante e tem se mostrado uma ameaça para a transmissão de valores positivos aos filhos, que favoreçam tanto a formação do capital humano quanto a transferência do capital social para as gerações mais jovens e impulsione as carreiras desses executivos.

\section{Metodologia de Pesquisa}

A abordagem utilizada nesta pesquisa foi qualitativa-interpretativa, pois possibilita investigar um fenômeno com maior amplitude e aprofundamento (Alves-Mazzotti \& Gewandsznajder, 1999). Godoy (1995) considera que, por não possuir uma estrutura rígida, os estudos qualitativos abrem espaço para que novas contribuições surjam a partir da imaginação e da criatividade dos investigadores. Esse tipo de pesquisa se adapta tanto ao fenômeno que se quer compreender quanto ao enfoque sistêmico escolhido. A contextualização das relações entre os componentes do sistema visado é um dos princípios do pensamento sistêmico, o qual responde pela possibilidade de se referir a fenômenos que são contingentes e históricos (White \& Epston, 1993).

Kets De Vries et al. (2009), ao destacarem o pressuposto sistêmico do observador como parte do sistema, sugerem que pesquisadores que trabalham com famílias empresárias não ignorem as suas emoções. Ao contrário, recomendam que as identifiquem, absorvam e utilizem como importantes fontes de dados.

O método escolhido foi o estudo de caso (Yin, 2001) de um grupo empresarial familiar, denominado de O. G., formado por três empresas em atividade e cinco desativadas, localizadas no estado de Minas Gerais, que passava pelo processo de transmissão da gestão da primeira para a segunda geração. $\mathrm{O}$ fundador possui duas filhas e dois filhos que participam da gestão das empresas.

A abordagem sistêmica requer um modo próprio de fazer a coleta, o registro das observações e a análise. No caso de fenômenos relacionais humanos, a narrativa é a fonte expressiva dos objetos de interesse. Na visão de White e Epston (1993), as narrativas são veiculadoras de crenças, valores e conhecimento de uma cultura, ao mesmo tempo em que a cultura é por elas definida. Neste estudo, as narrativas foram construídas dialogicamente com os sujeitos pesquisados, nas situações de entrevista em profundidade e nas visitas às instalações da empresa para a realização das entrevistas, o que 
possibilitou a observação da relação dos membros da família com o fundador e com os funcionários. As observações daí resultantes foram trianguladas, isto é, confrontadas e relacionadas entre si (Collis \& Hussey, 2005).

O roteiro de entrevista elaborado teve como propósito estimular os entrevistados a falarem sobre os temas: fatos históricos considerados especiais ou marcantes, relacionados à identificação do fundador como mito organizacional; cultura organizacional e comportamentos do mito fundador; características e evolução do mito organizacional; etapas e estágio do processo de sucessão.

As entrevistas foram realizadas na sede das empresas do Grupo O. G., gravadas e transcritas na íntegra. A escolha dos oito entrevistados se deu pelo critério de intencionalidade, uma vez que esses sujeitos detinham informações-chave. Para preservar suas identidades, os nomes reais foram substituídos pelo cargo ou posição na família. Assim, o fundador foi identificado como Fundador; os quatro membros da segunda geração foram identificados como Filha 1, Filha 2, Filho 3 e Filho 4; dois funcionários, um com 24 anos de empresa foi denominado Gerente e o outro com 18 anos foi denominado Vendedor; e um ex-funcionário foi denominado Ex-funcionário.

Os dados foram analisados por meio da técnica de análise de conteúdo do tipo temática (Franco, 2008), sendo os temas estabelecidos a posteriori: desconstrução do mito, desenvolvimento do Grupo O.G., e gestão da sucessão e estrutura.

Em síntese, foram observados os seguintes passos para a análise dos dados: transcrição das entrevistas; leitura das entrevistas transcritas; seleção dos trechos de interesse; definição das unidades de conteúdo (tema); recorte dos trechos selecionados por unidade de conteúdo; e redação final das unidades de conteúdo.

A abordagem qualitativa exige que os pesquisadores que a adotam demonstrem preocupações com o rigor com que pretendem conduzir suas investigações, no entanto, os critérios de validade e fidedignidade, utilizados na pesquisa tradicional, segundo Alves-Mazzotti e Gewandsznajder (1999), não são apropriados para tal finalidade. Lincoln e Guba (1985) propõem como alternativa o critério de credibilidade, adotando-se os procedimentos de permanência prolongada no campo, a triangulação dos dados e a checagem pelos pares, que são solicitados a apontar as falhas, pontos obscuros e vieses nas interpretações. Todos eles foram adotados nesta pesquisa, esclarecendo-se que se trata de um trabalho resultante de uma dissertação de mestrado avaliada por banca examinadora.

\section{Caracterização do Grupo Familiar}

O Grupo O.G. é formado por três empresas em atividade: Comércio de Ferro Velho, Comércio de Latarias e Comércio de Ferramentas Elétricas. A Empresa Comércio de Ferro Velho foi fundada em 1982, possui oito funcionários e atua no ramo de comércio de peças automotivas usadas. Os herdeiros responsáveis pela gestão dessa empresa são a Filha 1 e o Filho 4. A Filha 1 gerencia a área administrativo-financeira, e o Filho 4, as áreas comercial e de compras. A Comércio de Latarias é a segunda empresa do Grupo, foi fundada em 1991 e possui dez funcionários. A gestora dessa empresa é a Filha 2. A terceira empresa é a Comércio de Ferramentas, que foi fundada em 2001, e possuiu atualmente nove funcionários. Os principais produtos por ela comercializados são ferramentas elétricas para a construção civil. A gestão dessa empresa é de responsabilidade de Filho 3. O faturamento anual conjunto das empresas é de aproximadamente $\mathrm{R} \$ 2.500 .000,00$.

A primeira filha tem 37 anos, é casada, não tem filhos e graduou-se em Administração de Empresas. A segunda filha tem 35 anos, é solteira e também concluiu o curso de Administração de Empresas. O terceiro filho tem 33 anos, é casado, não tem filhos e concluiu o ensino médio. O quarto filho tem 31 anos, é casado, pai de um filho de um ano de idade e também possuiu ensino médio completo. 


\section{Desconstrução do Mito}

O Fundador do Grupo O. G. nasceu em 1951 e, como muitos empreendedores brasileiros, tem origem humilde; seu pai era chofer de táxi e a mãe, dona de casa. As dificuldades enfrentadas desde cedo o fizeram sonhar com a superação e deram origem ao desejo de construir uma família e dar aos filhos o conforto e a segurança que ele próprio não teve. Aos 14 anos de idade, começou a trabalhar como contínuo em uma empresa. Casou-se em 1972 e, em 1974, foi trabalhar em uma pequena empresa de construção e pavimentação. Depois de seis anos como encarregado geral, foi contratado por uma grande construtora nacional, e passou a gerenciar obras por todo o Brasil. O sucesso profissional é reputado à dedicação irrestrita ao trabalho, comportamento este que exigiu dos filhos e dos funcionários, gerando, posteriormente, em seu próprio negócio, a filosofia de que "a empresa vem em primeiro lugar", ou seja, antes da família (Kets De Vries et al., 2009, p. 56).

Dedicação, eu digo que dedicação total, absoluta, entendeu? Eu sempre digo isso para mim, que é dar mais do que te pede, sabe? Eu não me limitava a fazer aquilo que a empresa queria. Então, se era para chegar na usina às seis horas eu estava lá às cinco. Era uma dedicação total irrestrita, eu não media esforços.

O Fundador abriu seu próprio negócio em 1982, um comércio de peças automotivas usadas, em sociedade com o irmão mais velho. Dois anos depois, comprou as quotas do irmão e tornou-se o único proprietário da empresa Comércio de Ferro Velho. Sua esposa o ajudava na área administrativa e financeira, e os negócios prosperavam. Para sair do aluguel, comprou um terreno numa região da cidade ainda pouco habitada, onde antes funcionava um prostíbulo. Posteriormente, comprou outros terrenos ao redor, contrariando as opiniões de que aquele não era um bom local para ter-se um comércio. Seu pioneirismo estimulou a entrada de novas empresas do mesmo ramo na região, e permitiu que a empresa entrasse no estágio de maturação. De 1991 a 2001, o Fundador criou mais cinco empresas, a Comércio de Latarias e a Comércio de Ferramentas Elétricas, que ainda continuam em atividade, a Indústria de Reboques, a Comércio de Ferro Velho Dois e uma Lavanderia, que foram desativadas.

O sucesso obtido na gestão dos negócios permitiu que o Fundador fosse identificado como um mito, na percepção dos entrevistados, principalmente por ter empreendido com poucos recursos, ter multiplicado o patrimônio e por possuir uma visão apurada para novos negócios. As atitudes e os comportamentos que melhor caracterizam o Fundador, segundo os entrevistados, são: ousadia, visão de negócio, dedicação, capacidade de fazer algo dar certo, empreendedorismo e carisma no relacionamento com os funcionários.

O estágio de declínio desse mito começou em 2011, com a eclosão de conflitos entre o Fundador e seus filhos. Ao longo de sua história, o Fundador conduziu seus negócios com rigor e exigiu dos filhos e dos funcionários muita dedicação ao trabalho. Seu perfeccionismo e envolvimento profissional o afastaram do convívio com a família, e a criação dos filhos foi delegada para sua esposa. Esse comportamento gerou fortes ressentimentos por parte de todos, como foi possível identificar por meio das falas.

Em 2006, ele teve que reduzir sua carga de trabalho em função de problemas de saúde. Tanto Fundador quanto filhos atribuem o adoecimento à excessiva carga de trabalho e ao estresse dela decorrente. Por recomendação médica, afastou-se dos negócios na cidade e foi morar num sítio, onde acabou fundando uma empresa de suinocultura e produção de leite, que também se revelou bem sucedida, de acordo com os depoimentos. Foi nesse momento que os filhos assumiram a gestão dos negócios.

Estudos realizados por Kets De Vries et al. (2009) revelam que a maioria dos problemas existentes em empresas familiares resulta do fato de pais e filhos, involuntariamente, extravasarem seus conflitos na arena da empresa. Ainda de acordo com os autores, da perspectiva do pai-fundador, ao pensar na sucessão, é comum nutrir o desejo de que um ou mais filhos estejam com ele à frente dos 
negócios no futuro, o que justifica toda a dedicação à empresa e sua ausência do convívio familiar. Da perspectiva dos filhos, não é incomum que estes desenvolvam sentimentos ambivalentes em relação à empresa e ao pai; primeiro, porque muitas vezes tiveram que dedicar o tempo livre, como férias escolares, ao trabalho na empresa do pai; em segundo, porque os assuntos da empresa sempre vinham em primeiro lugar nos poucos momentos em que desfrutavam da companhia do progenitor. Por conseguinte, os filhos podem ver no empreendimento familiar o primeiro amor do pai, ao mesmo tempo em que a empresa se torna importante por proporcionar um meio de interagir e obter o amor paterno (Kets De Vries et al., 2009).

A filosofia empresa em primeiro lugar fez com que o Fundador passasse a ser admirado e identificado como um mito, num primeiro momento, mas o foco excessivo na empresa deixou-lhe pouco tempo e energia para se dedicar à família. A falta de consciência em relação a esse problema impediu o Fundador do Grupo O.G. de mudar a situação, gerando um progressivo afastamento da mulher e dos filhos, até resultar na separação do casal em 2008. Nesse mesmo ano, a empresa Indústria de Reboques começou a ter problemas nas áreas de produção e vendas. Temendo que a situação se agravasse, a gestora, Filha 1, solicitou a ajuda do pai. O pedido de socorro foi imediatamente atendido, pois o Fundador, envaidecido, sentiu que novamente se tornava importante para a empresa e que, finalmente, os filhos iriam reconhecer que ele era insubstituível nos negócios.

Esse caso nos revela como pais centralizadores e autoritários podem impedir o crescimento e amadurecimento dos sucessores na gestão. Ao agir de forma superprotetora e cerceadora, os patriarcas não estão transmitindo nenhum valor positivo aos filhos, pelo contrário, eles estão criando uma barreira para a transferência da organização para as gerações mais jovens e obstruindo as carreiras desses executivos (Kets De Vries et al., 2009). Esse prognóstico se confirma na tentativa frustrada dos herdeiros de exercerem suas capacidades empreendedoras. A única empresa criada por iniciativa dos filhos foi uma distribuidora de produtos lácteos, que atendia todo o norte de Minas e o Sul da Bahia. Isso aconteceu em 2007 e o pai não aprovou a decisão: "se tivessem perguntado minha opinião, não deixaria que investissem em algo com produtos perecíveis". Um ano depois, ela foi fechada, em função do baixo retorno financeiro.

Conforme Brundin, Nordvist e Melin (2011), e Vieira, Sousa e Roscoe (2012), organizações com traços de cultura autoritária, caracterizadas pela concentração de poder do fundador e pela falta de autonomia concedida aos filhos, inibem a proatividade e o empreendedorismo das futuras gerações, ameaçando fortemente o empreendedorismo transgeracional, ou seja, "os processos pelos quais uma família usa e desenvolve o espírito empreendedor e as capacidades da família para influenciar e criar novos fluxos de valor empresarial, financeiro e social ao longo das gerações" (Habbershon et al., 2011, p. 1).

De acordo com Sardeshmukh e Corbett (2011), uma parte da razão do insucesso das empresas familiares se deve à falta de disposição de fundadores e sucessores para a mudança. Outra parte se deve à inação, à relutância em buscar novas oportunidades. Casillas, Moreno e Barbero (2010) apontam que o conservadorismo resulta em ausência de crescimento e está associado à falta de proatividade da segunda geração de proprietários da empresa familiar. Para Kellermanns et al. (2008), manter o empreendedorismo da família significa reconhecer, prosseguir e explorar continuamente as oportunidades empresariais, de forma a alcançar a sustentabilidade no longo prazo.

Quando o Fundador do Grupo O. G. deixou os negócios no sítio, a produção e a comercialização da suinocultura e do leite paralisaram, ao passo que a empresa Indústria de Reboques teve uma melhora na situação financeira até ser vendida, no final do ano de 2009, por um "bom preço", como dito pelo Fundador. Novamente os filhos afastaram o pai da gestão e selaram a queda do mito.

"Fico constrangido de tomar certas iniciativas, impedido ao ponto... Eles [os filhos] me tiraram".

Em janeiro de 2010, a esposa do Fundador faleceu, aos 52 anos de idade, em razão de um aneurisma cerebral. A perda da mãe tornou as relações entre filhos e Fundador ainda mais distantes, 
contudo, eles se recusam a tocar no assunto. São esses não ditos, como nos ensina Prado (2000), que marcam o mito familiar. Eles podem ser mantidos ocultos por uma ou duas gerações, mas são sempre transmitidos para as seguintes,

por discursos complexos nos quais atitudes, comportamentos e mímicas dizem algo que as palavras calam. Tal transmissão se dá em um registro inconsciente, não se percebe exatamente o segredo, mas, sim, que o não dito corresponde a alguma coisa, como uma palavra apagada em um texto escrito (Prado, 2000, p. 59).

Os mitos se constituem de crenças compartilhadas, aceitas sem questionamento, como a história de constituição da família, do fundador e dos negócios familiares e, mesmo que os aspectos de falsidades sejam reconhecidos, eles ficam em segredo (Prado, 2000). O mito tem, portanto, duas funções na família: a de manter a concordância grupal e fortalecer os papéis de cada um, e a de defesa, "uma espécie de proteção à existência, na medida em que se promove um triunfo sobre as angústias, particularmente as de morte" (Prado, 2000, p. 33).

Os motivos apontados pelos filhos para afastar o pai da gestão foram apenas os de ordem racional e objetiva: divergências nas formas de conduzir os negócios, relacionadas ao planejamento e ao processo decisório. Como todo gestor centralizador, o Fundador sempre se guiou mais pela intuição do que pela ciência; suas ideias e desejos de investir poderiam até ser discutidos em família, mas normalmente ele tomava as decisões sozinho.

"Na cabeça ele tem as questões formuladas, mas, não existe um planejamento em papel. Não existe um planejamento participativo". (Filho 4).

A ausência de normas ou regras escritas, de valores internalizados, bem como de uma visão de futuro para os negócios, também são motivos apontados para justificar as divergências entre o Fundador e os novos gestores: "ter uma visão ou missão escritas e dependuradas na parede não valem de nada, principalmente quando não estão internalizadas por todos da empresa" (Filho 3).

Como argumentam Kets De Vries et al. (2009), a falta de amor e de ambiente receptivo é capaz de despertar, nos filhos, o sentimento de desconfiança quanto à própria capacidade de serem independentes, incentivando disputas para definir quem estará no controle. A conflituosa e enredada relação com o pai e a ligação interrompida com a mãe abalaram o desenvolvimento do senso de identidade dos filhos e se converteram num obstáculo a suas autonomias. Em famílias nas quais os conflitos pessoais não são resolvidos e há falta de confiança, as relações interpessoais se tornam complicadas e a rivalidade e a concorrência entre os filhos podem passar a ser o padrão dominante nas interações (Kets De Vries et al., 2009). Como alerta N. Nicholson (2008), a família é o mecanismo primário para a transmissão da identidade e dos valores dos proprietários familiares e gestores. Situações de descontinuidade dos afetos e abordagens excessivamente conservadoras e controladoras podem obscurecer as vantagens desse tipo de empreendimento, pois o trabalho em equipe entre os parentes é essencial para o crescimento da empresa; a cooperação e a coalizão são a cola que mantêm as pessoas juntas, gerando capital social e vantagem competitiva.

O estágio do mito no Grupo O.G. aponta para a sua desconstrução, uma vez que a falta de coesão entre os membros da família e os conflitos latentes têm levado os herdeiros a rejeitarem o progenitor e a desejarem mudanças de direção das empresas. Daí se faz necessário que as questões emocionais sejam expostas e conversadas, ao mesmo tempo em que regras claras de gestão e propriedade sejam estabelecidas, formalizadas e unanimemente aceitas entre os membros da família.

Em empresas familiares, é importante que os mitos sucessores aprendam a conviver com o mito do fundador, a fim de preservar a identidade e a coesão dos grupos, uma vez que culturas centradas no fundador (Hall, Melin, \& Nordqvist, 2001; Schein, 1983) podem promover a renovação e a transmissão do empreendedorismo às gerações sucessoras, desde que haja estimulação da autonomia e da proatividade dos seus membros (Brundin et al., 2011). A maior ameaça à perpetuação do espírito empreendedor na família está justamente na figura do Fundador autoritário, centralizador e ausente do 
processo de educação e aprendizagem das futuras gerações (Habbershon et al., 2011; N. Nicholson, 2008; Vieira et al., 2012).

Esses fatos revelam que as empresas familiares são, de fato, compostas por subsistemas superpostos, cada um com suas normas, regras, estrutura de valores e organização. Para compreender o que realmente ocorre no Grupo O.G., analisaremos como o estágio do mito está inter-relacionado com o desenvolvimento da empresa nas dimensões: família, propriedade e empresa.

\section{Desenvolvimento do Grupo O. G.}

A análise sistêmica do desenvolvimento do Grupo O. G. foi realizada por meio do modelo tridimensional de Gersick et al. (2006). Na dimensão propriedade, o Grupo encontra-se na transição do estágio inicial de proprietário controlador para o estágio de sociedade entre irmãos. O Fundador já venceu o desafio de escolher uma estrutura de propriedade para a próxima geração ao decidir que as empresas do Grupo continuarão em poder da família. Cada filho gerencia uma das empresas, no entanto não há uma divisão de quotas formalmente constituída. As decisões sobre dividendos, retiradas e reinvestimentos são tomadas individualmente por cada gestor e não são compartilhadas com os demais, o que revela a manutenção do padrão de relacionamento estabelecido pelo pai, centrado no distanciamento emocional, no controle e na submissão. $\mathrm{O}$ atual desafio do Grupo é conseguir ter um processo de gestão compartilhado entre os irmãos. Ao que tudo indica, conflitos psicológicos intensos tendem a se tornar um padrão regular de funcionamento nessa família, debilitando a comunicação, o compartilhamento de ideias, a discussão de problemas e a tomada de decisão eficaz.

"O patrimônio é de todo mundo, mas, funciona mais ou menos assim, o rendimento da empresa Comércio de Ferramentas Elétricas, hoje, é do Filho 3. Como ele administra, não presta contas, na verdade nunca foi pedido para ele a prestação de contas. É como se aquilo pertencesse a ele, era essa a ideia, que cada um cuidasse do seu" (Fundador).

Na dimensão empresa, o Grupo se encontra no estágio denominado expansão e formalização. Os maiores desafios dessa fase são o planejamento estratégico e o estabelecimento de políticas organizacionais. Em todas as empresas do Grupo O. G., a gestão é voltada para a manutenção e a sustentabilidade do negócio e sobrevivência da família, o processo de decisão é centralizado pelo gestor responsável e não há um grupo gestor ou uma diretoria formalmente estabelecida. Esse caso revela que a empresa está subordinada aos desejos da família e a prática de nepotismo está presente, uma vez que os membros familiares conquistaram cargos executivos valendo-se mais da condição de membro da família do que de seu potencial ou desempenho.

Na dimensão família, o Grupo está no quarto estágio, que é o da passagem do bastão. A transferência da liderança das empresas já aconteceu, mas sem o necessário planejamento do afastamento do Fundador, que deve incluir os procedimentos necessários para a transferência da liderança, e também dos aspectos jurídicos e financeiros (Ip \& Jacobs, 2006). É preciso um esforço deliberado e sistemático para planejar a sucessão em uma organização de forma a garantir a continuidade da liderança nas posições-chave, bem como o desenvolvimento do capital social e humano (Carter \& Schwab, 2008; Garg \& Weele, 2012; Molly, Laveren, \& Deloof, 2010).

Essa é a questão central abordada no presente artigo: a falta de preparação da segunda geração para a sucessão, bem como a necessária divisão da propriedade e a construção da governança, fatores que serão aprofundados no próximo item. 


\section{Gestão da Sucessão e da Estrutura}

Roibal, Solórzano, Carballo e Feijoó (2004) afirmam que os principais problemas enfrentados pelas empresas familiares, independentemente de sua localização geográfica, podem ser resumidos em dois grupos. No primeiro, estão aqueles derivados do funcionamento da empresa familiar, devido à confusão entre os fluxos empresariais e os interesses familiares; no segundo grupo, estão os problemas de sucessão, que, por sua vez, subdividem-se em dois subgrupos: os conflitos decorrentes da falta de definição de um plano de sucessão; e problemas fiscais, que derivam do pagamento de imposto e de doações para a próxima geração. Nós acrescentamos, ainda, outro subgrupo, inspirados no trabalho de Brenes et al. (2006), que é a gestão da estrutura, que inclui a governança, os acordos de acionistas e também a transferência de cotas da propriedade.

Iniciando pelo processo de sucessão, concordamos com De Freyman e Richomme-Huet (2010), que esse processo está fortemente associado aos modos e aos meios pelos quais o capital social é transferido para os gestores familiares da próxima geração, o que pode ocorrer, segundo os autores: de forma repentina; apressada; por imersão natural; e de forma planejada e com deliberada transferência do capital social.

No Grupo O. G., a sucessão aconteceu de modo não planejado, portanto, sem a necessária transferência de capital social, relacionado aos laços sociais, às relações de confiança e ao sistema de valores que facilitam a ação, a coordenação e a cooperação entre as partes, incluindo a rede social formada por clientes e fornecedores (De Freyman \& Richomme-Huet, 2010; De Freyman, RichommeHuet, \& Paturel, 2006). Também não houve qualquer planejamento para o desenvolvimento do capital humano, ou seja, para a educação dos sucessores nos aspectos cognitivos e comportamentais, atributos individuais que são complementares aos sociais.

No Grupo O. G., à medida que o filho participava das atividades da empresa e inspirava confiança, assumia posição de gerência. O aprendizado ocorreu na função por meio da observação e da tentativa de imitação das práticas do Fundador. A qualificação dos herdeiros não foi um critério para a ocupação de cargos, de acordo com os entrevistados. Por iniciativa própria, duas filhas se graduaram em Administração de Empresas. Já os filhos homens concluíram apenas o ensino médio, pois, assim como o pai, acreditam que "a prática é mais importante que a formação acadêmica" (Filho 3).

Sardeshmukh e Corbett (2011) argumentam que muitas empresas familiares perdem o potencial empreendedor ao longo do tempo em função da falta de capacidade de identificar oportunidades de crescimento, exatamente pela falta de aquisição de capital humano geral e específico. O capital geral é aquele desenvolvido fora dos negócios da família, e que traz novas informações e habilidades de aplicá-las em novos contextos, a fim de revigorar os negócios. O capital específico, por sua vez, permite ao sucessor adquirir habilidades que são relevantes naquele ambiente em particular, portanto, é desenvolvido dentro da empresa, estando fortemente relacionado à noção de autoeficácia, ou seja, à crença no sucesso pessoal. Trata-se de uma habilidade cognitiva importante para gerar abertura para se aventurar em novos negócios ou oportunidades estratégicas (Sardeshmukh \& Corbett, 2011). Assim sendo, a aceitabilidade, a credibilidade, a legitimidade e a liderança dos sucessores, como propõem Bayad e Barbot (2002), são conquistadas na medida em que a aprendizagem e a formação dos herdeiros potenciais estão presentes na organização.

O ingresso dos filhos ainda jovens nos negócios da família, no caso do Grupo O. G., foi um fator que facilitou o processo de sucessão; no entanto, algumas dificuldades ainda estão sendo enfrentadas, como as comparações do perfil do Fundador com o dos sucessores e a associação da expansão e do crescimento das empresas à imagem do mito.

\footnotetext{
"Aquela coisa mais de hábito, de ter estabelecido uma coisa de confiança entre fornecedores, clientes e empresa já existia. Então, quando eu comecei a fazer, por exemplo, o que meu pai fazia, as pessoas disseram: mas, cadê seu pai, mas cadê o Fundador?" (Filho 1).
} 
Os empregados, inicialmente, ficaram insatisfeitos com as mudanças, uma vez que, na percepção deles, os novos gestores não agem como o Fundador.

"Todos os dias, ao chegar à empresa de manhã, ele passava de funcionário em funcionário, em todas as áreas, para desejar um bom dia e fazer uma brincadeira. Isso acabou. Muitos pensaram até em pedir demissão". (Funcionário).

Essas falas revelam uma zona de desconfiança social, que corresponde a situações em que os interessados expressam um sentimento de rejeição para com o sucessor natural, revelando que a sucessão de uma geração para a próxima ocorre dentro de uma complexa teia de relações dinâmicas (De Freyman \& Richomme-Huet, 2010).

Como afirma Ziemer (1996), o mito tem um poder intrínseco, e sua história está entrelaçada com a da própria empresa e a de seus funcionários, por isso, mudar os mitos de uma organização, mesmo que eles sejam disfuncionais ou obsoletos, exige enfrentar oposições e resistências.

No que se refere à gestão da estrutura, os sucessores apropriaram-se de cargos gerenciais com o consentimento do Fundador, mas ainda não se constituíram legalmente como proprietários. A passagem para o estágio de sucessão madura, portanto, dependente de um planejamento dialogado entre os membros, com atenção às expectativas de cada um, e da formalização da propriedade entre os membros, tão importante para a efetiva sucessão quanto o capital humano e social (Brenes, Madrigal, \& Monila-Navarro 2006; De Freyman et al., 2006; De Freyman \& Richomme-Huet, 2010; Roibal, Solórzano, Carballo, \& Feijoó, 2004).

O modelo de gestão caracterizado pelo cada um cuida da sua empresa indica a dificuldade dos filhos de falarem sobre a divisão da propriedade e a sucessão do Fundador, pois isso fatalmente traria à tona a discussão sobre qual dos irmãos seria o escolhido ou estaria mais bem preparado para substituir o pai. Para o Fundador, essa situação não deixa de ser confortável, uma vez que seu cargo continua vago, alimentando o sonho do retorno, caso os filhos fracassem.

Quando questionado sobre os benefícios da formalização de um conselho familiar, o Fundador responde: "Você tocou num ponto, talvez o mais importante de toda a entrevista. Para mim, se houvesse isso, o patrimônio voltaria a crescer.... Nós retomaríamos todas as veias e as empresas cresceriam com isso á'”. No entanto, o mesmo se furtou a estabelecer as bases para a construção da estrutura quando ainda estava no poder, confirmando, portanto, que ele não contava com o adoecimento e nem cogitava a aposentadoria, forçada pelos filhos que o impedem de retornar.

De acordo com Garg e Weele (2012), as pequenas, micro e médias empresas familiares (PMME) tendem a acreditar que não precisam respeitar os códigos de governança, no entanto, estabelecer controles internos das atividades da empresa, alinhados às condições ambientais vivenciadas, é fundamental para que o empreendedorismo floresça.

Assim como Kets De Vries et al. (2009), argumentamos que as ações em empresas familiares, tanto no plano estrutural como no funcional, tais como a construção dos acordos societários, devem estar associadas a ações no plano terapêutico familiar, com a finalidade de alinhar os interesses da família e da empresa e permitir o processo de diferenciação dos indivíduos do ponto de vista emocional, definido nos termos psicodinâmicos como processo de separação-individuação (Mahler, Pine, \& Bergman, 1975) e apenas como diferenciação na teoria dos sistemas familiares de Bowen (1978). Significa, pois, buscar a diferenciação do self, ampliando a consciência de qualidades pessoais únicas, bem como do potencial de crescimento e de autonomia, para que cada indivíduo obtenha maior equilíbrio na vida emocional, desenvolva atividades orientadas por metas com comportamento responsável e distinga os sentimentos da realidade objetiva, recuperando-se com maior facilidade do estresse provocado por tensões e conflitos (Bowen, 1978). 


\section{Considerações Finais}

O objetivo geral da pesquisa consistiu em identificar os fatores que contribuem para a desconstrução de um mito em uma empresa familiar, e analisar como o estágio do mito se relaciona com o desenvolvimento sistêmico da organização nas dimensões: família, propriedade e empresa.

O fundador em questão foi considerado mito enquanto demostrou capacidade de realizar conquistas no âmbito empresarial em condições que pareciam muito difíceis ou inapropriadas, portanto, o caráter ousado de seus atos, mesmo dispondo de pouco capital, acabou por gerar o desejo de ser imitado. Nesse aspecto, os achados do estudo confirmam o que já tem sido apontado pela literatura.

No entanto, alguns fatores relacionados ao comportamento do mito acabaram por levar à sua desconstrução, tais como: a intensa dedicação à empresa associada à ausência do convívio familiar; a incapacidade do fundador de perceber e agir sobre os conflitos latentes, que geraram sentimentos de ressentimento em relação à empresa e ao próprio progenitor; a recusa em abordar temas difíceis que se transformam em não ditos e corroem os relacionamentos; a centralização e o autoritarismo na gestão, que levam à falta de estímulo à proatividade da geração sucessora; e a falta de atenção à necessidade de criação de um ambiente de aprendizagem que permita a transmissão do empreendedorismo para as futuras gerações.

Conclui-se que a filosofia empresa em primeiro lugar pode fazer com que o fundador seja admirado e identificado como um mito, num primeiro momento, mas o foco excessivo na empresa deixa pouco tempo e energia para que se dedique à família. A falta de consciência em relação a esse problema impediu o Fundador do Grupo O. G. de mudar a situação, gerando um progressivo afastamento afetivo e emocional dos sucessores. Associado a esse comportamento, a excessiva centralização e o autoritarismo impediram o amadurecimento profissional e emocional dos sucessores. Além disso, a superproteção e o cerceamento geraram barreiras para a transferência de conhecimento dos negócios e do espírito empreendedor entre as gerações. Foram esses os traços, portanto, que impediram o planejamento da sucessão.

Ao abdicar da convivência, do compartilhamento de experiências e do verdadeiro exercício da aprendizagem transgeracional, os patriarcas deixam de transmitir valores positivos aos filhos e, com a eclosão dos conflitos familiares, os mitos passam a ser questionados, rejeitados e afastados, permitindo a emergência de mitos concorrentes.

Observa-se, por fim, que o que compromete a sobrevivência desse negócio familiar e a união e a coesão dos membros dessa família são as questões afetivas e emocionais não abordadas por meio de um diálogo aberto. Conflitos latentes, alimentados por sentimentos negativos, agem como elementos corrosivos e desfazem as interações causando sofrimento, a ponto de desestabilizar o fundador-mito e fragilizar valores e crenças que são os alicerces sobre os quais a identidade coletiva é construída. O afastamento do fundador pode ser sustentado por argumentos de ordem racional e objetiva, como divergências nas formas de conduzir os negócios, no entanto, eles só fazem encobrir as questões de ordem subjetiva e emocional.

Essas constatações sustentam o argumento central deste trabalho, de que culturas centradas no fundador podem promover renovação quando a geração sucessora interage com o fundador nas decisões estratégicas; por outro lado, a ausência do fundador do convívio familiar, associada ao comportamento autoritário e centralizador, com baixa atenção às questões subjetivas na interação dos subsistemas família-propriedade-empresa, impedem a construção de um ambiente receptivo e afetivo, necessário para a aprendizagem, impedindo o desenvolvimento da autoconfiança necessária para a efetiva sucessão. Em síntese, quando os mitos sucessores não aprendem a conviver com o fundadormito, a preservação da identidade e da coesão do grupo ficam ameaçadas. 
Pensar sistemicamente a empresa familiar é importante, porque, apesar de os três subsistemas serem independentes, eles se relacionam entre si, e qualquer disfunção em um deles afetará os demais, às vezes, de maneira letal. Ao transitar sobre os subsistemas do Grupo O. G., verifica-se que, na dimensão propriedade, o Grupo se encontra no estágio inicial, de proprietário controlador, mas o desejo de substituir o fundador-mito tem levado à transição para o estágio de sociedade entre irmãos; na dimensão família, o Grupo está na fase de passagem do bastão, mesmo com a resistência do fundador-mito; e, por fim, na dimensão 'empresa', encontra-se em expansão/formalização, apesar da existência de conflitos latentes entre os membros da família.

Este estudo contribui para a geração de conhecimentos relativos às empresas familiares que levam em consideração nas suas análises os aspectos subjetivos e simbólicos que regem as relações entre os atores sociais envolvidos nesses processos. Contribui, também, para que empresas que estejam passando por processos de sucessão similares possam se beneficiar dos conhecimentos gerados, antecipando soluções.

Sugere-se que futuros estudos sobre a temática aprofundem o entendimento dos estágios de evolução dos fundadores-mitos e sua relação com o ciclo de vida das organizações, bem como investiguem as formas e os critérios de inserção dos sucessores em funções diretivas, adotados nas empresas familiares brasileiras.

\section{Referências}

Alves-Mazzotti, A. J., \& Gewandsznajder, F. (1999). O método nas ciências naturais e sociais: pesquisa quantitativa e qualitativa (2a ed.). São Paulo, SP: Pioneira.

Armstrong, K. (2005). Breve história do mito. São Paulo: Companhia das Letras.

Azevedo, A. V. (2004). Mito e psicanálise. Rio de Janeiro: Jorge Zahar.

Bayad, M., \& Barbot, M. C. (2002, outubro). Proposition d'un modèle de succession dans les PME familiales: étude de cas exploratoire de relation père-fille. Congrès International Francophone sur la PME, Montréal, CA, 6.

Borges, A. F., Carvalho, F. A. P., \& Lima, J. B. de (2007, setembro). Construção do processo de sucessão em empresas familiares: transmissão gerencial e patrimonial. Anais do Encontro Nacional da Associação Nacional de Pós-Graduação e Pesquisa em Administração, Rio de Janeiro, RJ, Brasil, 31.

Bowen, M. (1978). Family therapy in clinical practice. Jason Aronson: Northvale.

Brenes, E. R., Madrigal, K., \& Molina-Navarro, G. E. (2006). Family business structure and succession: critical topics in Latin American experience. Journal of Business Research, 59(3), 372-374. doi: 10.1016/j.jbusres.2005.09.011

Brundin, E., Nordqvist, M., \& Melin, L. (2011). Entrepreneurial orientation across generations in family firms: the role of owner-centric culture for proactiveness and autonomy. In M. Nordqvist \& T. M. Zellweger (Orgs.), Transgenerational entrepreneurship: exploring growth and performance in family firms across generations (pp. 123-141). Massachusetts, USA: Edward Elgar.

Cadieux, L. (2007). Succession in small and medium-sized family business: toward a typology of predecessor roles during and after instatement of the successor. Family Business Review, 20(2), 95-109. doi: 10.1111/j.1741-6248.2007.00089.x 
Carter, J., \& Schwab, A. (2008). Turnaround strategies in established small family firms. Family Business Review, 21(1), 31-50. doi: 10.1111/j.1741-6248.2007.00113.x

Casillas, J. C., Moreno, A. M., \& Barbero, J. L. (2010). A configurational approach of the relationship between entrepreneurial orientation and growth of family firms. Family Business Review, 23(1), 27-44. doi: 10.1177/0894486509345159

Casillas, J. C., Vásquez, A., \& Díaz, C. (2007). Gestão da empresa familiar: conceitos, casos e soluções. São Paulo: Thompson.

Chauí, M. (2000). Mito fundador e sociedade autoritária. São Paulo: Perseu Abramo.

Chittoor, R., \& Das, R. (2007). Professionalization of management and succession performance - a vital linkage. Family Business Review, 20(1), 65-79. doi: 10.1111/j.1741-6248.2007.00084.x

Collis, J., \& Hussey, R. (2005). Pesquisa em administração: um guia prático para alunos de graduação e pós-graduação. Porto Alegre: Bookman.

Davis, J., \& Tagiuri, R. (1989). Life stages and father-son work relations. Santa Barbara: Owner Management Institute.

De Freyman, J., \& Richomme-Huet, K. (2010). Entreprises familiales et phénomène successoral: pour une approche intégrée des modes de transmission. Revue Française de Gestion, 36(200), 161179. doi: $10.3166 /$ rfg.200.161-179

De Freyman, J., Richomme-Huet, K., \& Paturel, R. (2006, fevereiro). Condition model for transferring social capital in family business succession. Proceedings of the International Research Entrepreneurship Exchange, Auckland, Nouvelle-Zélande, 3.

Falcke, D., \& Wagner, A. (2005). A dinâmica familiar e o fenômeno da transgeracionalidade: definição e conceitos. In A. Wagner (Org.), Como se perpetua a família? A transmissão dos modelos familiares (pp. 25-46). Porto Alegre: EDIPUCRS.

Flores, J. E., Jr., \& Grisci, C. (2012). Dilemas de pais e filhos no processo sucessório. Revista de Administração, 47(2), 325-337. doi: 10.5700/rausp1042

Franco, M. L. P. B. (2008). Análise de conteúdo. Brasília, DF: Líber Livro.

Garg, A. K., \& Weele, E. van (2012). Succession planning and its impact on the performance of small micro medium enterprises within the manufacturing sector in Johannesburg. International Journal of Business and Management, 7(9), 96-107. doi: 10.5539/ijbm.v7n9p96

Gersick, K. E., Davis, J. A., Hampton, M., \& Lansberg, I. (2006). De geração para geração: ciclo de vida das empresas familiares. Rio de Janeiro: Elsevier.

Godoy, A. S. (1995). Pesquisa qualitativa: tipos fundamentais. Revista de Administração de Empresas, 35(3), 20-29. doi: 10.1590/S0034-75901995000300004

Gueiros, M. B., \& Oliveira, L. M. (2000, setembro). Sucessão familiar: prática em empresa de transporte - uma visão dos dirigentes. Anais do Encontro Nacional da Associação Nacional de Pós-Graduação e Pesquisa em Administração, Florianópolis, SC, Brasil, 24.

Habbershon, T. G., Nordqvist, M., \& Zellweger, T. M. (2011). Transgenerational entrepreneurship. In M. Nordqvist \& T. M. Zellweger (Eds.), Transgenerational entrepreneurship: exploring growth and performance in family firms across generations (pp. 1-38). Northampton, Massachusetts, USA: Edward Elgar Publishing. 
Hall, A., Melin, L., \& Nordqvist, M. (2001). Entrepreneurship as radical change in the family business: exploring the role of cultural patterns. Family Businesses Review, 14(3), 193-208. doi: 10.1111/j.1741-6248.2001.00193.x

Henriques, M. I. G., \& Gomes, I. C. (2005). Mito familiar e transmissão psíquica: uma reflexão temática de forma lúdica. Revista de Psicanálise Psyché, 9(16), 183-196.

Ip, B., \& Jacobs, G. (2006). Business succession planning: a review of the evidence. Journal of Small Business and Enterprise Development, 13(3), 236-350. doi: 10.1108/14626000610680235

Kellermanns, F. W., Eddleston, K. A., Barnett, T., \& Pearson, A. (2008). An exploratory study of family member characteristics and involvement: effects on entrepreneurial behavior in the family firm. Family Business Review, 21(1), 1-14. doi: 10.1111/j.1741-6248.2007.00107.x

Kets De Vries, M., Carlock, R. S., \& Florent-Treacy, E. (2009). A empresa familiar no divã: uma perspectiva psicológica. Porto Alegre: Bookman.

Lincoln, Y. S., \& Guba, E. G. (1985). Naturalistic inquire. New Bury Park, CA: Sage Publications.

Longenecker, J. G., Moore, C. W., \& Petty, J. W. (1997). Administração de pequenas empresas: ênfase na gerência empresarial. São Paulo: Makron Books.

Mahler, M. S., Pine, F., \& Bergman, A. (1975). The psychological birth of the human infant. New York: Basic Books.

Massis, A. de, Chua, J. H., \& Chrisman, J. J. (2008). Factors preventing intra-family succession. Family Business Review, 21(2), 183-199. doi: 10.1111/j.1741-6248.2008.00118.x

Molly, V., Laveren, E., \& Deloof, M. (2010). Family business succession and its impact on financial structure and performance. Family Business Review, 23(2), 131-147. doi: $10.1177 / 0894486510365062$

Nicholson, N. (2008). Evolutionary psychology and family business: a new synthesis for theory, research and practice. Family Business Review, 21(1), 103-118. doi: 10.1111/j.17416248.2007.00111.x

Nicholson, L., \& Anderson, A. R. (2005). News and nuances of the entrepreneurial myth and metaphor: linguistic games in entrepreneurial sense-making and sense-giving. Entrepreneurship, Theory and Practice, 29(2), 153-172. doi: 10.1111/j.15406520.2005.00074.x

Oliveira, V. C. de, Silva, P. J., Pereira, M. C., \& Brito, M. J. de (2008). Cultura e mito nas organizações: análise dos sentidos construídos sobre a morte de Roberto Marinho. Contemporânea, 6(2), 86-104.

Panichi, R. M. D. (2007). Mito e a narrativa da estrutura familiar sobre o tempo, o nascimento e a morte presentificados. Contemporânea-Psicanálise e Transdisciplinaridade, 3, 269-275.

Pontanari, J. (2008). Mito e psicanálise: quando eles nos vivem e quando nós os vivemos. Contemporânea - Psicanálise e Transdisciplinaridade, 5, 66-88.

Pontet, S. B. de, Wrosch, C., \& Gagne, M. (2007). An exploration of the generational differences in levels of control held among family business approaching succession. Family Business Review, 20(4), 337-354. doi: 10.1111/j.1741-6248.2007.00103.x

Prado, M. C. do (2000). Destino e mito familiar: uma questão na família psicótica. São Paulo: Vetor. 
Roibal, S. B., Solórzano, E. G., Carballo, M. M., \& Feijoó, G. D. (2004, outubro). Visión europea del processo de sucesión en la empresa familiar. Boletin Económico de ICE (2821), p. 11.

Rosa, M. D. (2001). O não dito familiar e a transmissão da história. Psychê Revista de Psicanálise, $5(8), 123-137$.

Sardeshmukh, S. R., \& Corbett, A. C. (2011). The duality of internal and external development of successors: opportunity recognition in family firms. Family Business Review, 24(2), 111-125. doi: $10.1177 / 0894486510391783$

Scheffer, A. B. B. (1995). Fatores dificultantes e facilitadores ao processo de sucessão familiar. Revista de Administração, 30(3), 80-90.

Schein, E. H. (1983). The role of the founder in creating organizational culture. Organizational Dynamics, 5(1), 13-28.

Tagiuri, R., \& Davis, J. (1996). Bivalent Attributes of the family firms. Family Business Review, 9(2), 199-208. doi: 10.1111/j.1741-6248.1996.00199.x

Vieira, A., Sousa, J. A., Neto, \& Roscoe, M. T. A. de (2012). The influence of culture on governance, innovativeness and knowledge generation in Brazilian family businesses. In M. Nordqvist, G. Marzano, E. R. Brenes, G. Jimenez, \& M. Fonseca-Paredes (Orgs.), Understanding entrepreneurial family businesses in uncertain environments: opportunities and resources in Latin America (pp. 66-90). Northampton, Massachusets, USA: Edward Elgar Publishing.

Waiandt, C., \& Davel, E. (2008). Organizações, representações e sincretismo: a experiência de uma empresa familiar que enfrenta mudança e sucessão de gestão. Revista de Administração Contemporânea, 12(2), 369-394. doi: 10.1590/S1415-65552008000200005

White, M., \& Epston, D. (1993). Medios narrativos para fines terapêuticos. Buenos Aires: Paidós.

Yin, R. K. (2001). Estudo de caso: planejamento e métodos. Porto Alegre: Bookman.

Ziemer, R. (1996). Mitos organizacionais: o poder invisível na vida das empresas. São Paulo: Atlas. 